Original paper

\title{
Variant etiologies of neonatal cholestasis and their outcome: a Middle East single-center experience
}

\author{
Mohamed Abdel-Salam El-Guindi', Magdy Anwar Saber', Samar Ahmed Shoeir', Ayat Roushdy Abdallah², \\ Ahmad Mohamed Sira ${ }^{1}$ \\ 'Department of Pediatric Hepatology, Gastroenterology, and Nutrition, National Liver Institute, Menoufia University, Egypt \\ 2Department of Epidemiology and Preventive Medicine, National Liver Institute, Menoufia University, Egypt
}

\begin{abstract}
Aim of the study: Neonatal cholestasis (NC) constitutes a large proportion of pediatric liver disorders. Nevertheless, awareness of the variant etiologies and how to manage them appropriately are lacking. So, out of a few specialized centers, many cases pass without appropriate management. This study aimed to present our tertiary level center's experience in NC that could increase the pediatrician's awareness of handling this problematic and common medical morbidity efficiently.

Material and methods: It is a retrospective study in which we analyzed the NC cases admitted to the inpatient department within three years. For all recruited patients, the available data were retrieved and recorded.

Results: A total of 412 patients were reviewed with 20 different etiologies diagnosed. The most common cause was biliary atresia $(n=151,37 \%)$, followed by progressive familial intrahepatic cholestasis $(n=51,12 \%)$, neonatal sepsis $(n=39,9 \%)$, and cytomegalovirus $(n=33,8 \%)$. Of the 412 patients, 394 (81\%) had follow-up ranging from 1 to 36 months. A total of 173 patients improved with supportive and/or specific therapy, while 108 patients died at a median age of 6 months. The commonest cause of death was liver failure (40.7\%), followed by pneumonia (28.7\%), sudden death (13\%), septicemia (6.5\%), and hepatorenal syndrome (5.5\%).

Conclusions: NC constitutes more than one-third of the inpatient admissions of all pediatric liver disorders and has a high rate of mortality. Awareness of the variety of etiologies and a rapid stepwise approach to diagnosis could have an impact on the outcome of this devastating disease.
\end{abstract}

Key words: biliary atresia, idiopathic neonatal hepatitis, Kasai portoenterostomy, progressive familial intrahepatic cholestasis.

\section{Address for correspondence:}

Dr. Ahmad Mohamed Sira, Department of Pediatric Hepatology, Gastroenterology, and Nutrition, National Liver Institute, Menoufia University, Egypt, e-mail: asira@liver.menofia.edu.eg

\section{Introduction}

Neonatal cholestasis (NC) is a group of disorders characterized by direct hyperbilirubinemia with variable degrees of liver dysfunction. There are a plethora of etiologies that can present with $\mathrm{NC}$, making it difficult to manage. The prevalence of the various etiologies varies from one region to another [1]. Knowledge of the most common etiologies and their natural course could facilitate a stepwise approach for the rapid diagnosis and appropriate management of infants with NC, especially in developing countries with limited resources.

Many studies have described the characteristics and outcomes of the various causes of NC in different countries [2-6]. However, some of these studies either reported a small number of cases $[4,7]$ or did not report on patient follow-up [7]. Moreover, the final diagnosis sometimes lacked accuracy such as those referred to as giant cell hepatitis [4], which is not a diagnosis, but rather a pathological picture with multiple etiologies. 
Little is known about the epidemiology of NC in Middle Eastern countries. Delineation of the various etiologies from a large cohort of cases with a description of the various disease characteristics, courses, and outcomes can provide the necessary background for a stepwise approach to NC. This study aimed to describe our tertiary level center's longterm experience with a large cohort of NC cases and their long-term follow-up.

\section{Material and methods}

\section{Study population}

This was a retrospective, cohort study in which we analyzed NC patients admitted to the Department of Pediatric Hepatology, Gastroenterology, and Nutrition in our tertiary level center from July 1, 2012 to June 30, 2015. Follow-up data on the recruited patients were accumulated through December 31, 2016. This study was approved by the Research Ethics Committee and conformed to the 1975 Declaration of Helsinki and its later amendments.

Of the 2183 admissions to the unit during the duration of the study, 773 admissions had a diagnosis of NC which consisted of 435 individual patients. Patients with multiple admissions during the study period were counted as one case. A total of 23 cases were excluded due to

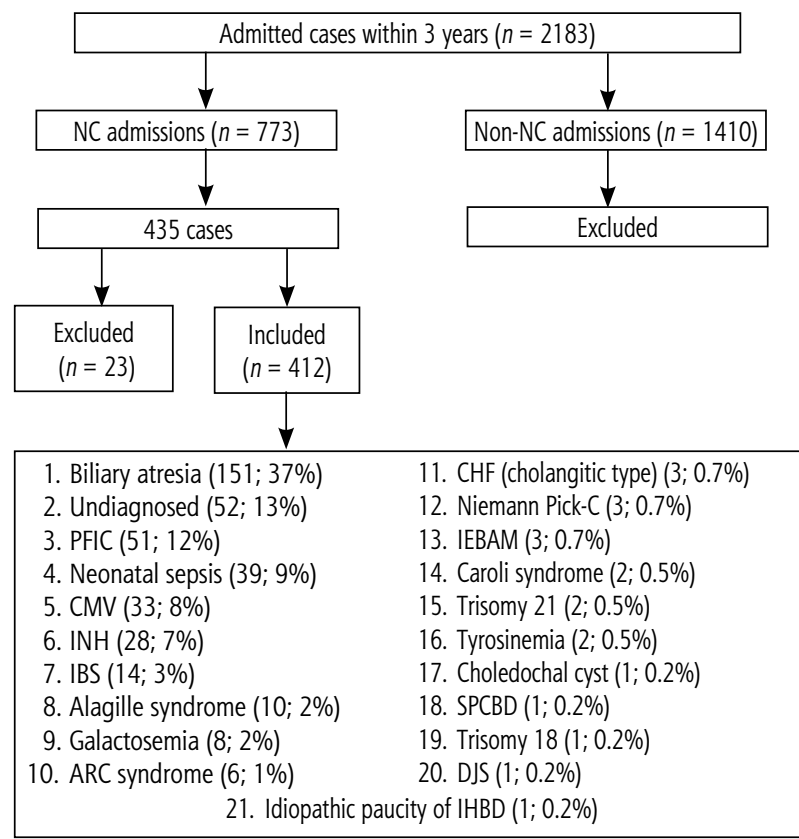

$A R C$ - arthrogryposis-renal-cholestasis syndrome, CHF - congenital hepatic fibrosis, CMV - cytomegalovirus, DJS - Dubin-Johnson syndrome, IEBAM - inborn error of bile acid metabolism, IBS - inspissated bile syndrome, IHBD - intrahepatic bile duct, INH - idiopathic neonatal hepatitis, NC - neonatal cholestasis, PFIC - progressive familial intrahepatic cholestasis, SPCBD - spontaneous perforation of common bile duct

Fig. 1. Included and excluded cases within the study with different variants of the reported neonatal cholestasis etiologies insufficient data in their files. Ultimately, a total of 412 patients were reviewed (Fig. 1).

\section{Etiological diagnosis}

Biliary atresia (BA) was diagnosed according to suggestive clinical, laboratory, radiological, and pathological criteria we reported before [8] and confirmed by laparotomy \pm intraoperative cholangiogram (IOC). Cases that fulfilled all of the BA criteria and excluded all other possible etiologies but did not have the diagnosis confirmed by laparotomy were labeled as proposed BA. BA cases that underwent a Kasai portoenterostomy (KP) operation before the study began and were subsequently readmitted during the study period were labeled post-Kasai.

Progressive familial intrahepatic cholestasis (PFIC) was diagnosed based on the phenotypic presentation, the presence of a positive family history, pruritus out of proportion to cholestasis, high serum bile acids, low $\gamma$-glutamyl transferase (GGT) for types 1 and 2 , and high GGT for type 3, with suggestive pathological criteria [9]. Neonatal sepsis (NS) was diagnosed when cholestasis was associated with a systemic inflammatory response in the presence of, or due to, bacterial infection with isolation of the organism by culture and the exclusion of other causes of NC [10].

The diagnosis of congenital cytomegalovirus (CMV) hepatitis was established by isolation of the virus in blood within the first three weeks of life. Perinatal CMV hepatitis was diagnosed by positive serology and DNA with the exclusion of other etiologies of NC together with suggestive pathological features. All other etiologies were diagnosed based on the presence of specified diagnostic criteria [11].

Idiopathic neonatal hepatitis (INH) was diagnosed after excluding various infectious, metabolic, endocrine, anatomical, and genetic causes of NC [11]. The undiagnosed group was labeled as such based on: 1) no follow-up in most of these cases, 2) not completing requested investigations due to parental non-compliance or the cost of the studies, 3) early death before completing the diagnostic workup, and 4) insufficient data in the patient's records.

\section{Statistical analysis}

Quantitative variables were expressed as mean \pm standard deviation or a median (minimum-maximum) depending on the nature of the data, while qualitative variables were expressed as the number (percentage) of individuals with a condition. For quantitative data, statistical significance was tested by the independent 
samples $t$-test or by the non-parametric Mann-Whitney $U$ test as indicated. The significance of qualitative data was tested with the $\chi^{2}$ test or Fisher's exact test. Results were considered significant if the $P$-value was $<0.05$. Statistical analysis was performed using SPSS, version 16 (SPSS Inc., Chicago, IL, USA).

\section{Results}

\section{Etiology of neonatal cholestasis}

The etiology of NC for the included cohort was categorized into 20 different categories. The most frequent cause was BA $(n=151,37 \%)$, followed by the undiagnosed category $(n=52,13 \%)$, PFIC $(n=51,12 \%)$, NS $(n=39,9 \%)$, CMV $(n=33,8 \%)$, INH $(n=28,7 \%)$, and others (Fig. 1).

\section{Demographic and clinical characteristics at presentation}

Age at presentation ranged from 4 to 400 days with a median of 60 days. Nine patients (seven patients with PFIC and two patients with proposed BA) first presented at age over one year. Although they had the onset of jaundice early in their life, they first presented to our department at this late age due to a lack of parental orientation to seek medical advice. Females constituted $45 \%$ of all patients. A positive family history was reported in $7 \%$ of all cases, but none in BA $(p=0.001)$. The onset of jaundice was substantially earlier in those with BA $(p=0.003)$. Clay-colored stool, intracranial hemorrhage $(\mathrm{ICH})$, and hepatomegaly were significantly higher in the BA group (Table 1). Infants with PFIC had a significantly higher incidence of clay-colored stool than other non-BA cases $(37.3 \%$ vs. $20.5 \%, p=0.012)$.

\section{Laboratory parameters at presentation}

At presentation, total bilirubin ranged from $3 \mathrm{mg} / \mathrm{dl}$ to $46 \mathrm{mg} / \mathrm{dl}$ with a median of $11 \mathrm{mg} / \mathrm{dl}$, and no significant difference was found between the BA and the nonBA groups. However, albumin, alkaline phosphatase, GGT, platelets, and bile acids were significantly higher in the BA group. Transaminase levels varied over a wide range from $10 \mathrm{U} / 1$ to $2655 \mathrm{U} / 1$ for alanine aminotransferase (ALT) and from $19 \mathrm{U} / \mathrm{l}$ to $2117 \mathrm{U} / \mathrm{l}$ for aspartate aminotransferase (AST). However, only a few categories were associated with transaminase levels > $1000 \mathrm{U} / \mathrm{l}$, specifically NS, CMV hepatitis, PFIC-2, and galactosemia. Other laboratory parameters are noted in Table 2.

\section{Liver biopsy}

Of the recruited 412 patients, 284 underwent liver biopsy. Correlation of the pathological diagnosis with the final diagnosis was significantly higher in the BA group than the non-BA group $(p=0.001)$. The provisional pathological diagnosis was consistent with the definitive diagnosis for $86 \%$ of BA patients.

\section{Endoscopic duodenal examination}

A total of 143 patients (99 with proven BA, and 44 without BA) with clay-colored stool underwent endoscopic examination of the duodenum for the presence of bile. All the BA patients $(n=99,100 \%)$ and $28(63.6 \%)$ of those with non-BA cholestasis showed no bile in the duodenum at the time of examination, while $16(36.4 \%)$ of the non-BA patients had bile in the duodenum.

\section{Outcomes}

A total of $334(81 \%)$ patients were followed for a duration ranging from 1 to 36 months, and 78 (19\%) patients did not return for follow-up. Of the $334 \mathrm{pa}-$ tients who were followed up, 173 (51.8\%) improved with supportive \pm specific therapy and 108 patients (32.3\%) died. Of the remaining patients, $4.2 \%$ had no change in their clinical status and $11.7 \%$ experienced a deterioration of their clinical status. The outcomes and follow-up duration for specific etiologies are noted in Table 3.

Moreover, it was found that the undiagnosed group had the worst outcome with the highest percentage of deaths (59\%) followed by BA (43\%). On the other hand, the IBS had the best outcome with $100 \%$ improvement, followed by the INH (92\%) (Table 4).

\section{Causes of mortality for different etiologies}

The median age at death for the 108 (26\%) patients who died was 6 months with a range of 1-48 months. The most common cause of death was liver failure (40.7\%), followed by pneumonia (28.7\%), sudden death $(13 \%)$, and septicemia (6.5\%). Causes of death by etiology of NC are noted in Table 5 .

\section{Characteristics of biliary atresia}

A total of 104 patients (25.2\%) were diagnosed with BA confirmed by laparotomy and/or IOC. Of these, 103 had a KP, while one patient's procedure was canceled due to the presence of ascites detected intraop- 
Table 1. Demographic and clinical characteristics of all neonatal cholestasis (NC), biliary atresia (BA), and non-BA cholestasis

\begin{tabular}{|c|c|c|c|c|}
\hline Variable & $\begin{array}{c}\text { All NC } \\
(n=412)\end{array}$ & $\begin{array}{c}\text { BA } \\
(n=104)\end{array}$ & $\begin{array}{c}\text { Non-BA } \\
(n=261)\end{array}$ & $P$ value \\
\hline Age (days) & $60(4-400)$ & $60(22-150)$ & $60(4-400)$ & 0.613 \\
\hline Sex (females) & $186(45.1 \%)$ & $50(48.1 \%)$ & 112 (42.9\%) & 0.370 \\
\hline Family history & $29(7 \%)$ & $0(0 \%)$ & $28(10.7 \%)$ & 0.001 \\
\hline Consanguinity & $96(23.3 \%)$ & $10(9.6 \%)$ & 75 (28.7\%) & $<0.001$ \\
\hline \multicolumn{5}{|l|}{ Onset of jaundice: } \\
\hline $1^{\text {st }}$ week & 374 (90.8\%) & $102(98 \%)$ & $225(86.2 \%)$ & \multirow[t]{4}{*}{0.003} \\
\hline $2^{\text {nd }}$ week & $14(3.4 \%)$ & $0(0 \%)$ & $14(5.4 \%)$ & \\
\hline $3^{\text {rd }}$ week & $17(4.1 \%)$ & $1(1 \%)$ & $16(6.1 \%)$ & \\
\hline $5^{\text {th }}$ week & $7(1.7 \%)$ & $1(1 \%)$ & $6(2.3 \%)$ & \\
\hline Clay stool & 211 (51.2\%) & $104(100 \%)$ & $62(24 \%)$ & $<0.001$ \\
\hline Pruritus & 69 (16.7\%) & $4(3.8 \%)$ & $63(24.1 \%)$ & $<0.001$ \\
\hline Melena & $9(2.2 \%)$ & $1(1 \%)$ & $5(1.9 \%)$ & 0.679 \\
\hline Bleeding diathesis & $36(8.7 \%)$ & $10(9.6 \%)$ & $23(8.8 \%)$ & 0.809 \\
\hline Edema & $24(5.8 \%)$ & $2(1.9 \%)$ & $18(6.9 \%)$ & 0.059 \\
\hline Encephalopathy & $11(2.7 \%)$ & $0(0 \%)$ & $7(2.7 \%)$ & 0.311 \\
\hline $\mathrm{ICH}$ & $10(2.4 \%)$ & $7(6.7 \%)$ & $3(1.1 \%)$ & 0.007 \\
\hline NLF presentation & $23(5.6 \%)$ & $0(0 \%)$ & $23(8.8 \%)$ & $<0.001$ \\
\hline Hepatomegaly & $346(84 \%)$ & $102(98.1 \%)$ & $197(75.5 \%)$ & $<0.001$ \\
\hline Splenomegaly & 135 (32.8\%) & $26(25 \%)$ & 71 (27.2\%) & 0.667 \\
\hline Ascites & $34(8.3 \%)$ & $0(0 \%)$ & $25(9.6 \%)$ & 0.030 \\
\hline Skeletal anomalies & $21(5.1 \%)$ & $0(0 \%)$ & $21(8 \%)$ & 0.003 \\
\hline Cataract & $1(0.2 \%)$ & $0(0 \%)$ & $1(0.38 \%)$ & 1 \\
\hline Cardiac anomalies & $29(7 \%)$ & $4(3.8 \%)$ & $24(9.2 \%)$ & 0.083 \\
\hline PS & $6(1.5 \%)$ & $0(0 \%)$ & $6(2.3 \%)$ & \\
\hline PDA & $5(1.2 \%)$ & $0(0 \%)$ & $5(1.9 \%)$ & \\
\hline PFO & $5(1.2 \%)$ & $2(1.9 \%)$ & $3(1.1 \%)$ & \\
\hline VSD & $4(1 \%)$ & $0(0 \%)$ & $3(1.1 \%)$ & \\
\hline ASD & $4(1 \%)$ & $1(1 \%)$ & $3(1.1 \%)$ & \\
\hline Fallot trilogy & $2(0.5 \%)$ & $0(0 \%)$ & $2(0.8 \%)$ & \\
\hline$P S+V S$ & $1(0.2 \%)$ & $0(0 \%)$ & $1(0.4 \%)$ & \\
\hline PDA + VSD & $1(0.2 \%)$ & $1(1 \%)$ & $0(0 \%)$ & \\
\hline \multicolumn{5}{|l|}{ Other anomalies } \\
\hline Situs inversus totalis & $6(1.4 \%)$ & $4(3.9 \%)$ & $0(0 \%)$ & \multirow[t]{4}{*}{ NA } \\
\hline Choledochal cyst & $2(1.9 \%)$ & $2(1.9 \%)$ & $0(0 \%)$ & \\
\hline Duodenal atresia & $1(1 \%)$ & $1(1 \%)$ & $0(0 \%)$ & \\
\hline Hydrocephalus & $2(1.9 \%)$ & $2(1.9 \%)$ & $0(0 \%)$ & \\
\hline
\end{tabular}

$P$-value is for comparison between $B A$ and non $B A$ groups.

$B A$ group includes only cases that proved to be $B A$ with the exclusion of probable cases.

The Non-BA cholestasis group includes all NC cases except proved $B A(n=104)$, proposed $B A(n=41)$, and post-Kasai cases $(n=6)$.

eratively. Another 41 patients (10\%) were thought to have BA but this was not confirmed by laparotomy due to late presentation.

\section{Outcome of Kasai portoenterostomy}

Of the 103 patients who underwent a KP, only 86 had post-operative follow-up, with a median of 
Table 2. Laboratory parameters of all neonatal cholestasis (NC), biliary atresia (BA), and non-BA cholestasis at presentation

\begin{tabular}{|c|c|c|c|c|}
\hline Parameter & $\begin{array}{c}\text { All NC } \\
(n=412)\end{array}$ & $\begin{array}{c}\text { BA } \\
(n=104)\end{array}$ & $\begin{array}{c}\text { Non-BA } \\
(n=261)\end{array}$ & $P$ value \\
\hline Total bilirubin (mg/dl) & $11(3-46)$ & $10.5(6-23)$ & $10(3-46)$ & 0.799 \\
\hline Direct bilirubin (mg/dl) & $7(2-31)$ & $8(3-17)$ & $7(2-30)$ & 0.626 \\
\hline Total proteins (g/dl) & $5.1 \pm 0.8$ & $5.2 \pm 0.6$ & $5.1 \pm 0.8$ & 0.084 \\
\hline Albumin (g/dl) & $3.4 \pm 0.6$ & $3.6 \pm 0.4$ & $3.4 \pm 0.6$ & 0.001 \\
\hline $\operatorname{ALT}(\mathrm{U} / \mathrm{I})$ & $122(10-2655)$ & $105(19-461)$ & $127(10-2655)$ & 0.101 \\
\hline AST (U/I) & $203(19-2117)$ & $175(67-586)$ & $222(19-2117)$ & 0.073 \\
\hline $\operatorname{ALP}(U / I)$ & $450(19-2680)$ & $530(200-2145)$ & $420(19-2680)$ & 0.001 \\
\hline GGT (U/I) & $276(7-3540)$ & $820(132-3540)$ & $140(7-2060)$ & $<0.001$ \\
\hline INR & $1.0(1-6)$ & $1.0(1-2)$ & $1.0(1-6)$ & $<0.001$ \\
\hline PTT (s) & $34(20-120)$ & $20(20-55)$ & $34(20-120)$ & 0.001 \\
\hline $\mathrm{Hb}(\mathrm{g} / \mathrm{dl})$ & $9.5 \pm 1.8$ & $9.3 \pm 1.3$ & $9.6 \pm 2.1$ & 0.217 \\
\hline $\operatorname{TLC}\left(\times 10^{3} / \mathrm{mm}^{3}\right)$ & $12(4-59)$ & $12(4-30)$ & $12(5-59)$ & 0.477 \\
\hline Platelets $\left(\times 10^{3} / \mathrm{mm}^{3}\right)$ & $345(4-1,076)$ & $440(78-900)$ & $330(4-1,076)$ & $<0.001$ \\
\hline $\operatorname{AFP}(\mathrm{ng} / \mathrm{ml})$ & $4398(1-136,565)$ & $2500(76-80,000)$ & $5783(1-136,565)$ & 0.019 \\
\hline Ferritin (ng/ml) & $696(8-42,078)$ & 587 (56-5094) & $932(8-42,078)$ & 0.037 \\
\hline Bile acids (mmol/l) & $122(1-579)$ & $276(39-482)$ & $119(1-579)$ & 0.076 \\
\hline \multicolumn{5}{|c|}{ Reducing substance in urine } \\
\hline Not tested & $348(84.5 \%)$ & $103(99 \%)$ & $205(78.5 \%)$ & \multirow[t]{3}{*}{ NA } \\
\hline Negative & $52(12.6 \%)$ & $1(1 \%)$ & $46(17.6 \%)$ & \\
\hline Band of galactose & $12(2.9 \%)$ & $0(0 \%)$ & $10(3.8 \%)$ & \\
\hline \multicolumn{5}{|l|}{ Galactose I phosphate } \\
\hline Not tested & $352(85.4 \%)$ & $103(99 \%)$ & $208(79.7 \%)$ & \multirow[t]{3}{*}{ NA } \\
\hline Positive & $8(4 \%)$ & $1(1 \%)$ & $7(2.7 \%)$ & \\
\hline Negative & $52(12.6 \%)$ & $0(0 \%)$ & $46(17.6 \%)$ & \\
\hline \multicolumn{5}{|l|}{ Succinyl acetone in urine } \\
\hline Not tested & $353(85.7 \%)$ & $103(99 \%)$ & $207(79.3 \%)$ & \multirow[t]{3}{*}{ NA } \\
\hline Negative & $57(13.8 \%)$ & $1(1 \%)$ & $52(19.9 \%)$ & \\
\hline Positive & $2(1 \%)$ & $0(0 \%)$ & $2(0.8 \%)$ & \\
\hline
\end{tabular}

P-value is for comparison between $B A$ and non $B A$ groups.

$B A$ group includes only cases that proved to be $B A$ with the exclusion of probable cases.

The non-BA cholestasis group includes all NC cases except proved $B A(n=104)$, proposed $B A(n=41)$, and post-Kasai cases $(n=6)$.

6 months. A total of 37 patients (43\%) had a successful outcome, and 49 (57\%) patients had failed outcomes [12]. There were no significant differences between either group in demographic, clinical, preoperative laboratory, virologic, radiologic, or histopathologic data $(p>0.05$, for all). There was a higher rate of post-operative ascending cholangitis in the successful group $(83 \%$ vs. $33 \%, p<0.001)$.

\section{Discussion}

Neonatal cholestasis presents a significant burden of morbidity. If not properly managed, it can lead to significant complications or even death. Without understanding the magnitude of this problem, management strategies may be sub-optimal. NC has been studied in different countries [1, 2, 4-6, 13]; however, little is known about the magnitude and various etiologies of the disease in Middle Eastern countries. In the present study, the large number (412 patients) and high percentage of NC ( $35 \%$ of all admissions) relative to other pediatric liver disorders reflect the magnitude of this problem.

The etiology of NC might vary between different parts of the world [14]. When the frequency of specific etiologies causing cholestasis in the present study was 
Table 3. Outcome of different etiologies for cases which had a follow-up

\begin{tabular}{|c|c|c|c|c|c|}
\hline \multirow{2}{*}{$\begin{array}{l}\text { Etiology } \\
\text { (number of cases with follow-up/ } \\
\text { total number) }\end{array}$} & \multirow{2}{*}{$\begin{array}{l}\text { Follow-up duration } \\
\text { (months) }\end{array}$} & \multirow{2}{*}{$\begin{array}{c}\text { Improved } \\
n(\%)\end{array}$} & \multicolumn{2}{|c|}{ Did not improve } & \multirow{2}{*}{$\begin{array}{l}\text { Died } \\
n(\%)\end{array}$} \\
\hline & & & $\begin{array}{c}\text { Stationary } \\
n(\%)\end{array}$ & $\begin{array}{c}\text { Deteriorated } \\
n(\%)\end{array}$ & \\
\hline Total (334/412) & $4(1-36)$ & $173(51.8)$ & $14(4.2)$ & $39(11.7)$ & $108(32.3)$ \\
\hline \multicolumn{6}{|l|}{$\mathrm{BA}(118 / 151)$} \\
\hline Confirmed (86/104) & $6(1-36)$ & $34(39.5)$ & $6(7)$ & $18(20.9)$ & $28(32.6)$ \\
\hline Post Kasai (6/6) & $12(4-24)$ & $2(33.3)$ & $1(16.7)$ & $0(0)$ & $3(50)$ \\
\hline Proposed (26/41) & $4(1-24)$ & $0(0)$ & $1(3.8)$ & $5(19.2)$ & $20(76.9)$ \\
\hline Undiagnosed (22/52) & $3(1-24)$ & $3(13.6)$ & $1(4.5)$ & $5(22.7)$ & $13(59.1)$ \\
\hline \multicolumn{6}{|l|}{ PFIC (46/51) } \\
\hline Proved (28/30) & $12(1-24)$ & $16(57.1)$ & $16(57.1)$ & $5(17.9)$ & $5(17.9)$ \\
\hline Proposed (18/21) & $5(1-36)$ & $10(55.6)$ & $0(0)$ & $1(5.6)$ & $7(38.9)$ \\
\hline Neonatal sepsis (38/39) & $1(1-24)$ & $23(60.5)$ & $0(0)$ & $0(0)$ & $15(39.5)$ \\
\hline CMV (31/33) & $4(1-36)$ & $24(77.4)$ & $1(3.2)$ & $1(3.2)$ & $5(16.1)$ \\
\hline INH (27/28) & $2(1-36)$ & 25 (92.6) & $0(0)$ & $1(3.7)$ & $1(3.7)$ \\
\hline IBS (14/14) & $2.5(1-36)$ & $14(100)$ & $0(0)$ & $0(0)$ & $0(0)$ \\
\hline Alagille syndrome $(8 / 10)$ & $9.5(2-24)$ & $4(50)$ & $1(12.5)$ & $2(25)$ & $1(12.5)$ \\
\hline Galactosemia (8/8) & $3(1-5)$ & $7(87.5)$ & $0(0)$ & $1(12.5)$ & $0(0)$ \\
\hline ARC syndrome $(6 / 6)$ & $1(1-2)$ & $0(0 \%)$ & $0(0)$ & $0(0)$ & $6(100)$ \\
\hline $\operatorname{CHF}(3 / 3)$ & $12(12-24)$ & $2(66.7)$ & $1(33.3)$ & $0(0)$ & $0(0)$ \\
\hline $\operatorname{NPC}(3 / 3)$ & $4(3-24)$ & $3(100)$ & $0(0)$ & $0(0)$ & $0(0)$ \\
\hline IEBAM (2/3) & $4(1-7)$ & $2(100)$ & $0(0)$ & $0(0)$ & $0(0)$ \\
\hline Caroli syndrome (2/2) & $13(8-18)$ & $0(0)$ & $0(0)$ & $1(50)$ & $1(50)$ \\
\hline Trisomy 21 (1/2) & 1 & $1(100)$ & $0(0)$ & $0(0)$ & $0(0)$ \\
\hline Tyrosinemia (1/2) & 12 & $0(0)$ & $0(0)$ & $0(0)$ & $1(100)$ \\
\hline Choledochal cyst (1/1) & 3 & $0(0)$ & $0(0)$ & $0(0)$ & $1(100)$ \\
\hline $\operatorname{DJS}(0 / 1)$ & 0 & - & - & - & - \\
\hline SPCBD (1/1) & 12 & $1(100)$ & $0(0)$ & $0(0)$ & $0(0)$ \\
\hline Trisomy 18 (1/1) & 1 & $0(0)$ & $1(100)$ & $0(0)$ & $0(0)$ \\
\hline Idiopathic paucity (1/1) & 1 & $0(0)$ & $0(0)$ & $0(0)$ & $1(100)$ \\
\hline
\end{tabular}

ARC - arthrogryposis-renal-cholestasis syndrome, BA - biliary atresia, CHF - congenital hepatic fibrosis, CMV - cytomegalovirus, DJS - Dubin-Johnson syndrome, IEBAM - inborn error of bile acid metabolism, IBS - inspissated bile syndrome, INH - idiopathic neonatal hepatitis, NPC - Niemann-Pick type C, PFIC - progressive familial intrahepatic cholestasis, $S P C B D$ - spontaneous perforation of common bile duct

evaluated, BA was the single most common cause of NC (35.2\%), followed by PFIC (12.4\%).

In a retrospective study in Germany, Hoerning et al. [4] studied 82 infants with NC from January 2009 to April 2013. They noted 19 different etiologies causing NC. The most prevalent etiology was BA (41.5\%), followed by metabolic/genetic causes (16\%). Lee et al. [5] reviewed 146 patients with NC over a 7.5year period in Malaysia. They noted 16 different etiologies, the most common of which was BA (29\%).

In prospective studies in India, Yachha et al. [6] and more recently Poddar et al. [13] studied 60 and 101 pa- tients with NC, respectively. BA was reported to be the most common cause, $55 \%$ and $35 \%$, respectively. In Thailand, Aanpreung et al. [2] studied 252 cases with NC diagnosed over an 11-year period from 1993 to 2004 . They reported that the most common causes were INH (22.9\%) and BA (22.2\%).

The results of the present study and previous studies all found that BA should be considered first in the differential diagnosis of $\mathrm{NC}$, especially in patients with clay-colored stool. Of note, a clay-colored stool was found in $24 \%$ of patients with non-BA cholestasis. The most frequent etiology for a clay-colored stool in non- 
Table 4. Comparison among different etiologies regarding the outcome

\begin{tabular}{|c|c|c|c|c|c|c|c|c|c|}
\hline Outcome & $\begin{array}{c}\text { BA } \\
(n=118)\end{array}$ & $\begin{array}{c}\text { PFIC } \\
(n=46)\end{array}$ & $\begin{array}{c}\text { NS } \\
(n=38)\end{array}$ & $\begin{array}{c}\text { CMV } \\
(n=31)\end{array}$ & $\begin{array}{c}\text { INH } \\
(n=27)\end{array}$ & $\begin{array}{l}\text { Undiagnosed } \\
\quad(n=22)\end{array}$ & $\begin{array}{c}\text { IBS } \\
(n=14)\end{array}$ & $\begin{array}{c}\text { Others } \\
(n=38)\end{array}$ & $P$ value \\
\hline Died & $51(43)$ & $12(26)$ & $15(40)$ & $5(16)$ & $1(4)$ & $13(59)$ & $0(0)$ & $11(29)$ & $<0.001$ \\
\hline Improved & $38(32)$ & $26(57)$ & $23(60)$ & $24(78)$ & $25(92)$ & $3(14)$ & $14(100)$ & $20(53)$ & $<0.001$ \\
\hline Stationary & $8(7)$ & $2(4)$ & $0(0)$ & $1(3)$ & $0(0)$ & $1(4)$ & $0(0)$ & $2(5)$ & 0.724 \\
\hline Deteriorated & $21(18)$ & $6(13)$ & $0(0)$ & $1(3)$ & 1 (4) & $5(23)$ & $0(0)$ & $5(13)$ & 0.007 \\
\hline
\end{tabular}

BA - biliary atresia, CMV - cytomegalovirus, IBS - inspissated bile syndrome, INH - idiopathic neonatal hepatitis, NS - neonatal sepsis, PFIC - progressive familial intrahepatic cholestasis

Table 5. Causes of death for different etiologies

\begin{tabular}{|c|c|c|c|c|c|c|c|c|}
\hline Etiology & $\begin{array}{l}\text { Age of death } \\
\text { (months) }\end{array}$ & Liver failure & Pneumonia & $\begin{array}{l}\text { Intestinal } \\
\text { obstruction }\end{array}$ & Septicemia & HRS & Bleeding & $\begin{array}{l}\text { Sudden } \\
\text { death }\end{array}$ \\
\hline Total (108) & $6(1-48)$ & $44(40.7)$ & $31(28.7)$ & $4(3.7)$ & $7(6.5)$ & $6(5.5)$ & $2(1.9)$ & $14(13)$ \\
\hline \multicolumn{9}{|l|}{$\mathrm{BA}(51)$} \\
\hline Confirmed (28) & $12(2-24)$ & $10(35.7)$ & $9(32.1)$ & $4(14.3)$ & $4(14.3)$ & $1(33.3)$ & & $1(3.6)$ \\
\hline Post Kasai (3) & $19(12-36)$ & & $2(66.7)$ & & & $2(10)$ & & \\
\hline Proposed (20) & $12(3-36)$ & $15(75)$ & $2(10)$ & & & & $1(5)$ & \\
\hline Undiagnosed (13) & $3.5(1-17)$ & $7(53.8)$ & $2(15.4)$ & & $1(7.7)$ & & & $3(23.1)$ \\
\hline \multicolumn{9}{|l|}{$\operatorname{PFIC}(12)$} \\
\hline Proved (5) & $9(3-18)$ & $2(40)$ & $1(20)$ & & & $2(40)$ & & \\
\hline Proposed (7) & $10(6-24)$ & $2(28.6)$ & $2(28.6)$ & & $1(14.3)$ & $1(14.3)$ & $1(14.3)$ & \\
\hline NS (15) & $1.9 \pm 0.56$ & $4(26.7)$ & $9(60)$ & & & & & $2(13.3)$ \\
\hline CMV (5) & $2(1-9)$ & $3(60)$ & $2(40)$ & & & & & \\
\hline INH (1) & 4 & & & & & & & $1(100)$ \\
\hline AGS (1) & 12 & & $1(100)$ & & & & & \\
\hline $\operatorname{ARC}(6)$ & $2.7 \pm 0.5$ & & & & $1(16.7)$ & & & $5(83.3)$ \\
\hline Caroli syndrome (1) & 12 & $1(100)$ & & & & & & \\
\hline Tyrosinemia (1) & 48 & & $1(100)$ & & & & & \\
\hline Choledochal cyst (1) & 5 & & & & & & & $1(100)$ \\
\hline Idiopathic paucity (1) & 2 & & & & & & & $1(100)$ \\
\hline
\end{tabular}

AGS - Alagille syndrome, ARC - arthrogryposis-renal-cholestasis syndrome, BA - biliary atresia, CMV - cytomegalovirus, INH - idiopathic neonatal hepatitis, NS - neonatal sepsis, PFIC - progressive familial intrahepatic cholestasis

BA cholestasis was PFIC. Therefore, PFIC should be the first consideration in any case with clay-colored stool once BA has been excluded.

In contrast to these reports, Stormon et al. [15] noted that INH was the most common cause of NC (25\%), followed by metabolic/genetic disorders (23\%). In the present study, INH constituted only $7 \%$ of all NC patients. Many patients previously classified with $\mathrm{INH}$ have now been diagnosed more definitively due to the introduction of new diagnostic tools [5]. Hoerning et al. [4] reported a decreased percentage of INH (13\%).

Despite recent advances in investigational methods, reaching a definitive diagnosis is still challenging due to phenotypic similarities of different etiologies. A minimum of essential investigations are necessary for every patient, followed by more specific studies [16]. In the present study, $12.6 \%$ of patients were undiagnosed because they did not complete the required investigations. This high percentage highlights the importance of an expert approach to complete the diagnostic workup rapidly.

In the present study, we reported a mortality rate of $32.3 \%$. An additional $11.7 \%$ of patients had a deteriorating course for their disease. Lee et al. [5] reported $25 \%$ mortality in their NC patients, Hoerning et al. [4] reported a $12 \%$ mortality rate, while Yachha et al. [6] reported a $44 \%$ mortality rate among their patients with operated BA. The relatively high mortality rate in the present study could be attributed to the late presentation and consequently a late diagnosis of many 
BA cases. Other factors likely included the high rate of extrahepatic infections, the severity of liver decompensation, and a shortage of livers available for transplantation in our patients.

The reports noted above confirm the medical burden of NC and the need for proper diagnostic and treatment strategies. Even if a specific etiology for NC could not be determined, complications such as ICH can be ameliorated by starting supportive treatment as soon as possible [11]. This is illustrated by the fact that 10 infants $(2.4 \%)$ in the present study presented with $\mathrm{ICH}$, with a significantly higher rate among those with BA $(p=0.007)$. This highlights the importance of vitamin $\mathrm{K}$ administration without waiting for a specific etiological diagnosis.

Liver function tests do not contribute to a specific diagnosis except for a few exceptions such as a low GGT in PFIC [9] or an elevated GGT at different cutoff values in BA $[8,17]$. In the present study, transaminases were $>1,000 \mathrm{U} / 1$ in only $9(2.2 \%)$ cases. The etiologies of these cases were CMV hepatitis, NS, PFIC-2, and galactosemia. Although generally nonspecific, at times these tests may point to a specific etiology.

In the present study, $86 \%$ of patients pathologically diagnosed with BA were found to have that as a final diagnosis. Rastogi et al. [16] reported a high accuracy (88\%) for liver biopsy in diagnosing BA. Understanding this sensitivity and specificity of liver biopsy should not lead to an overdependence on the pathology. Instead, the final diagnosis in NC is a summation of clinical, laboratory, imaging, and pathological evaluation.

Ten patients diagnosed preoperatively with BA in fact had a patent biliary tree on IOC. The final diagnoses of these initially misdiagnosed cases were congenital hepatic fibrosis, Alagille syndrome, CMV hepatitis, and PFIC-3. Sira et al. [18] reported similar results for cases initially misdiagnosed as BA. A meticulous preoperative workup should be performed to exclude other causes of $\mathrm{NC}$, even if signs of BA are present. Our recently designed BA score [8], together with an endoscopic duodenal examination for bile, can avoid this misdiagnosis.

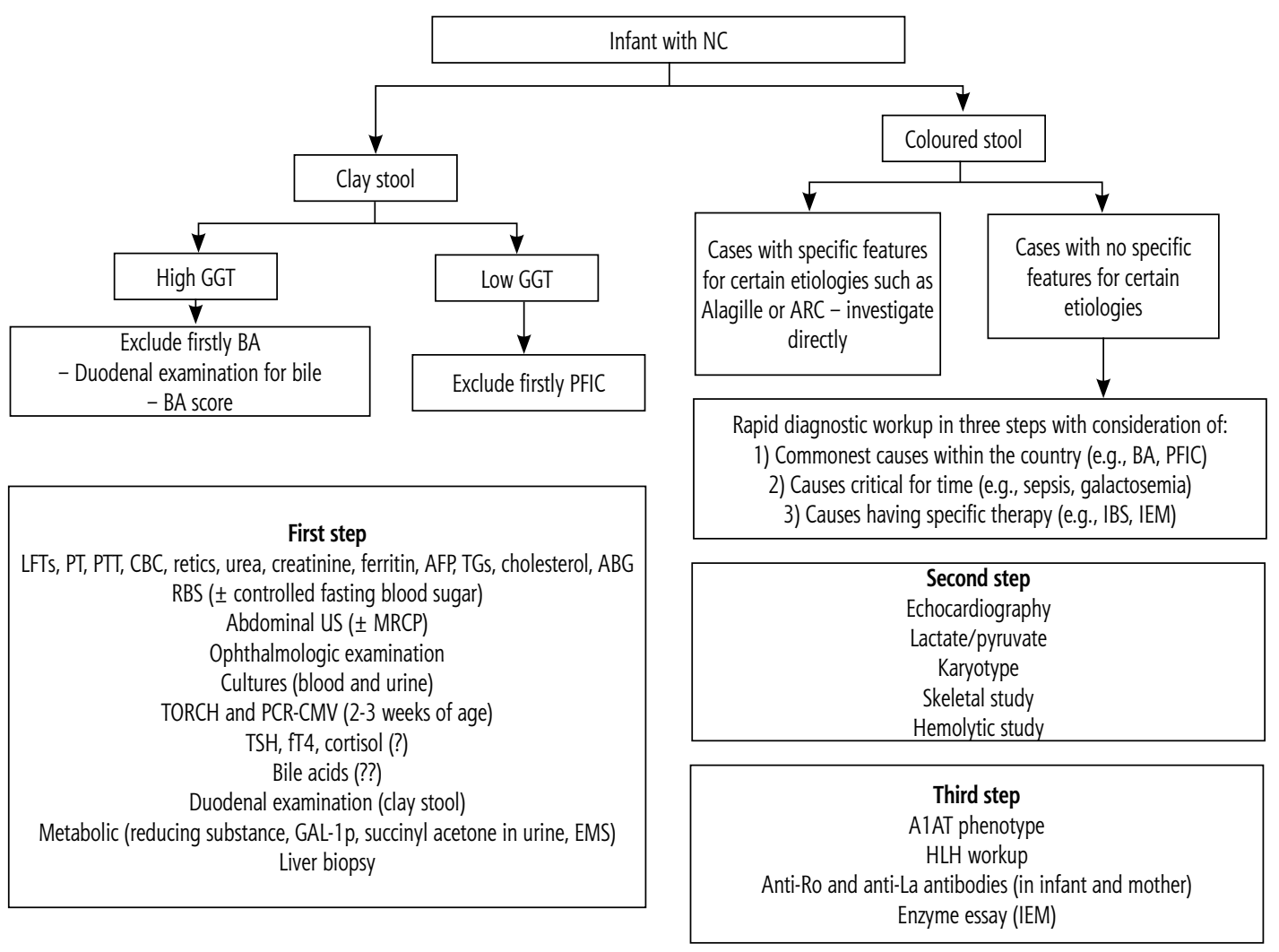

ATAT - $\alpha 1$ antitrypsin, ABG - arterial blood gases, AFP - $\alpha$-fetoprotein, BA - biliary atresia, CBC - complete blood count, EMS - extended metabolic screen, fT4 - free thyroxin, GAL-1p - galactose-1 phosphate, GGT - $\gamma$-glutamyl transferase, HLH - hemophagocytic lymphohistiocytosis, IBS - inspissated bile syndrome, IEM - inborn error of metabolism, LFTs - liver function tests, MRCP - magnetic resonance cholangiopancreatography, PCR-CMV - polymerase chain reaction for cytomegalovirus, PFIC - progressive familial intrahepatic cholestasis, PT - prothrombin time, PTT - partial thromboplastin time, RBS - random blood sugar, TGS - triglycerides, TORCH - Toxoplasma, Rubella, Cytomegalovirus, Herpes simplex, and others, TSH - thyroid-stimulating hormone, US - ultrasound

Fig. 2. Algorithm for a diagnostic approach to neonatal cholestasis 
Many algorithms have been published to guide the diagnostic approach for NC $[11,19]$. However, none are entirely accurate for reaching a specific etiology. In our experience, the diagnostic approach should consider: 1) the most common etiologies within a particular area, 2) etiologies that are time critical, and 3) causes that have a specific therapy. Based on the reported frequency of different etiologies, the diagnostic workup should be performed rapidly but in a three-step approach, and guided by the simple proposed algorithm in Fig. 2 .

The present study's strength is analyzing a large cohort of NC cases with a long period of follow-up. Moreover, the designed simple algorithmic approach for the etiological diagnosis based on long-term experience $[8,9,17,18,20-28]$ is another crucial point.

\section{Conclusions}

In conclusion, $\mathrm{NC}$ constitutes one of the most challenging presentations requiring differential diagnosis. It is not easy to differentiate between NC's various etiologies without a comprehensive workup. It is imperative to investigate and rule out common causes of cholestasis in the neonate, guided by an expert, simple, algorithmic approach. This approach is time-saving, as specific treatment, if delayed in certain conditions such as hypothyroidism, galactosemia, and BA, impairs survival.

\section{Acknowledgments}

We would like to thank the residents and nursing staff of the Pediatric Hepatology, Gastroenterology, and Nutrition Department for their contributions.

\section{Disclosure}

The authors declare no conflict of interest.

\section{References}

1. Gottesman LE, Del Vecchio MT, Aronoff SC. Etiologies of conjugated hyperbilirubinemia in infancy: a systematic review of 1692 subjects. BMC Pediatr 2015; 15: 192.

2. Aanpreung P, Laohapansang M, Ruangtrakool R, et al. Neonatal cholestasis in Thai infants. J Med Assoc Thai 2005; 88 Suppl 8: S9-15.

3. Dani C, Pratesi S, Raimondi F, et al. Italian guidelines for the management and treatment of neonatal cholestasis. Ital J Pediatr 2015; 41: 69.

4. Hoerning A, Raub S, Dechene A, et al. Diversity of disorders causing neonatal cholestasis - the experience of a tertiary pediatric center in Germany. Front Pediatr 2014; 2: 65.

5. Lee WS, Chai PF, Boey CM, et al. Aetiology and outcome of neonatal cholestasis in Malaysia. Singapore Med J 2010; 51: $434-439$.
6. Yachha SK, Khanduri A, Kumar M, et al. Neonatal cholestasis syndrome: an appraisal at a tertiary center. Indian Pediatr 1996; 33: 729-734.

7. Chowdhury FR, Chowdhury K, Karim A. Cholestatic jaundice in infants - an experience in tertiary care hospital. J Bangladesh Coll Phys Surg 2014; 32: 9-15.

8. El-Guindi MA, Sira MM, Sira AM, et al. Design and validation of a diagnostic score for biliary atresia. J Hepatol 2014; 61: 116-123.

9. Sira AM, Sira MM. Progressive familial intrahepatic cholestasis. In: Abdeldayem H (Ed.). Hepatic surgery. InTech 2013; 563-588.

10. Moseley RH. Sepsis and cholestasis. Clin Liver Dis 2004; 8: 83-94.

11. Hartley J. The Jaundiced Baby. In: Kelly DA (Ed.). Diseases of the liver and biliary system in children. 4th ed. John Wiley \& Sons Ltd, UK 2017; 99-126.

12. Bezerra JA, Spino C, Magee JC, et al. Use of corticosteroids after hepatoportoenterostomy for bile drainage in infants with biliary atresia: the START randomized clinical trial. JAMA 2014; 311: 1750-1759.

13. Poddar U, Thapa BR, Das A, et al. Neonatal cholestasis: differentiation of biliary atresia from neonatal hepatitis in a developing country. Acta Paediatr 2009; 98: 1260-1264.

14. Kagalwalla AF, Al Amir AR, Khalifa A, et al. Progressive familial intrahepatic cholestasis (Byler's disease) in Arab children. Ann Trop Paediatr 1995; 15: 321-327.

15. Stormon MO, Dorney SF, Kamath KR, et al. The changing pattern of diagnosis of infantile cholestasis. J Paediatr Child Health 2001; 37: 47-50.

16. Rastogi A, Krishnani N, Yachha SK, et al. Histopathological features and accuracy for diagnosing biliary atresia by prelaparotomy liver biopsy in developing countries. J Gastroenterol Hepatol 2009; 24: 97-102.

17. El-Guindi MA, El-Said HH, Hussein MH, et al. Urinary urobilinogen in biliary atresia: A missed, simple and cheap diagnostic test. Hepatol Res 2016; 46: 174-182.

18. Sira MM, Taha M, Sira AM. Common misdiagnoses of biliary atresia. Eur J Gastroenterol Hepatol 2014; 26: 1300-1305.

19. Bhatia V, Bavdekar A, Matthai J, et al. Management of neonatal cholestasis: consensus statement of the Pediatric Gastroenterology Chapter of Indian Academy of Pediatrics. Indian Pediatr 2014; 51: 203-210.

20. Behairy BE, Konswa HA, Ahmed HT, et al. Serum ferritin in neonatal cholestasis: A specific and active molecule or a non-specific bystander marker? Hepatobiliary Pancreat Dis Int 2019; 18: 173-180.

21. El-Araby HA, Saber MA, Radwan NM, et al. Temporal histopathological changes in biliary atresia: A perspective for rapid fibrosis progression. Ann Hepatol 2021; 21: 100263.

22. El-Guindi MA, Sira MM, Hussein MH, et al. Hepatic immunohistochemistry of bile transporters in progressive familial intrahepatic cholestasis. Ann Hepatol 2016; 15: 222-229.

23. El-Guindi MA, Sira MM, Konsowa HA, et al. Value of hepatic subcapsular flow by color Doppler ultrasonography in the diagnosis of biliary atresia. J Gastroenterol Hepatol 2013; 28: 867-872.

24. Ghoneim EM, Sira MM, Abd Elaziz AM, et al. Diagnostic value of hepatic intercellular adhesion molecule-1 expression in Egyptian infants with biliary atresia and other forms of neonatal cholestasis. Hepatol Res 2011; 41: 763-775.

25. Goda SS, Khedr MA, Elshenawy SZ, et al. Preoperative serum IL-12p40 is a potential predictor of Kasai portoenterostomy 
outcome in infants with biliary atresia. Gastroenterol Res Pract 2017; 2017: 9089068.

26. Sira MM, El-Guindi MA, Saber MA, et al. Differential hepatic expression of CD56 can discriminate biliary atresia from other neonatal cholestatic disorders. Eur J Gastroenterol Hepatol 2012; 24: 1227-1233.

27. Sira MM, Sira AM. Interleukin-17 in a mouse model of biliary atresia and in livers of patients: the study control matters. Gastroenterology 2016; 150: 1691-1692.

28. Sira MM, Sira AM, Ehsan NA, et al. P-Selectin (CD62P) expression in liver tissue of biliary atresia: a new perspective in etiopathogenesis. J Pediatr Gastroenterol Nutr 2015; 61: 561-567. 